\title{
Stimulation in vivo of expression of intra-abdominal adipose tissue plasminogen activator inhibitor Type I by proinsulin
}

\author{
T. K. Nordt ${ }^{1}$, C. Bode ${ }^{1}$, B. E. Sobel ${ }^{2}$ \\ ${ }^{1}$ Department of Cardiology, University of Freiburg, Freiburg, Germany \\ ${ }^{2}$ Department of Medicine, University of Vermont College of Medicine, Colchester Research Facility, Colchester, Vermont, USA
}

\section{Abstract}

Aims/hypothesis. Impaired fibrinolytic system capacity secondary to increased plasminogen activator inhibitor type-1 expression has been suggested as a pathogenetic link between insulin resistance and increased cardiovascular risk in patients with Type II (non-insulin-dependent) diabetes mellitus, obesity, or both. In patients with syndromes of insulin resistance including those with Type II diabetes, precursors of insulin such as proinsulin can constitute more than $50 \%$ of insulin-like molecules in blood. The aim of this study was to determine whether proinsulin can increase plasminogen activator inhibitor type- 1 expression in intra-abdominal adipose tissue in vivo, potentially contributing to the increased PAI-1 seen with insulin resistance.

Methods. Lightly sedated normal rabbits were given intravenous proinsulin, insulin, or vehicle alone under euglycaemic clamp conditions with serial sam- pling of blood and assessment of PAI-1 expression in visceral fat.

Results. Both proinsulin and insulin increased expression of plasminogen activator inhibitor type-1 in intra-abdominal adipose tissue, 5.3-fold ( $p=0.006$ vs control) and 2.5-fold ( $p=0.031$ vs control) respectively. PAI-1 inhibitor activity in blood peaked $3 \mathrm{~h}$ after administration of each, 5.1-fold, $p=0.020$, and 3.4 -fold, $p=0.004$, respectively but did not change under control conditions.

Conclusion/interpretation. Hyperproinsulinaemia can contribute to increased expression of plasminogen activator inhibitor type- 1 in intra-abdominal adipose tissue implicated in increasing PAI-1 activity in blood, impaired fibrinolysis, and accelerated atherogenesis typical of Type II diabetes. [Diabetologia (2001) 44: 1121-1124]

Keywords Diabetes mellitus, obesity, insulin, plasminogen activators, atherosclerosis.
The incidence of coronary artery disease is markedly increased in patients with insulin resistance such as

Received: 21 March 2001 and in revised form: 21 May 2001

Corresponding author: Burton E.Sobel, M.D. Professor \& Chair, Department of Medicine, University of Vermont College of Medicine, Colchester Research Facility, 208 So. Park Drive, Colchester, VT 05446, E-mail: burton.sobel@vtmednet.org Abbreviations: ANOVA, analysis of variance; AU, arbitrary unit; GAPDH, glyceraldehyde phosphate dehydrogenase; $\mathrm{kb}$, kilobases; mRNA, messenger ribonucleic acid; PAI-1, plasminogen activator inhibitor type-1; RNA, ribonucleic acid; rRNA, ribosomal ribonucleic acid; SEM, standard error of the mean; TNF- $\alpha$, tumour necrosis factor alpha; t-PA, tissuetype plasminogen activator those with Type II (non-insulin-dependent) diabetes mellitus or obesity. Reduced endogenous fibrinolytic system capacity secondary to increased expression of plasminogen activator inhibitor type-1 (PAI-1) has been implicated as one of multiple aetiologic factors [1]. Insulin can stimulate PAI-1 synthesis in adipocytes in vitro and in vivo $[2,3]$. In insulin resistant subjects, proinsulin can constitute more than $50 \%$ of the total of insulin-like molecules in blood [4]. This study was designed to determine whether proinsulin can contribute to increased expression of PAI-1 in intra-abdominal adipose tissue in vivo thereby potentially augmenting PAI-1 concentrations in blood resulting, in part, from PAI-1 originating in visceral fat. Rabbits were studied because of well established 
parallels between the fibrinolytic systems in rabbits and humans $[5,6]$.

Proinsulin given intravenously is not converted to insulin appreciably within the first $24 \mathrm{~h}$ after its administration [7]. Its effect on PAI-1 expression was compared with that of insulin. Visceral, rather than subcutaneous, adipose tissue was characterized because others have shown that intra-abdominal adipose tissue is a determinant of blood concentrations of PAI-1 and that PAI-1 production in human intraabdominal adipose tissue-explants is substantially greater than that in subcutaneous fat explants from the same subjects [8].

\section{Materials and methods}

Materials. Human insulin (26 U/mg) and glucose were purchased from Sigma (St. Louis, Mo., USA). Human proinsulin was provided by Eli Lilly (Indianapolis, Ind., USA). Contamination with endotoxin was excluded in all reagents and vehicles by testing with Limulus amebocyte lysate (Pyrotell assay, Associated of Cape Cod; sensitivity for detection of endotoxin, $0.0125 \mathrm{ng} / \mathrm{ml})$.

Procedures in animals. Care and handling of rabbits conformed with the guidelines of the University of Freiburg Committee on Human Care of Laboratory Animals and with the Declaration of Helsinki Standards. New Zealand White rabbits $(3.7 \pm 0.5$ $\mathrm{kg}$ body weight, mean $\pm \mathrm{SD}$ ) were tranquillized and maintained as described previously [6]. Anesthesia was avoided to preclude physiologic stress, consequent release of corticosteroids, catecholamines, and other hormonal derangements, resulting in increased free fatty acid concentrations in blood and hyperlipidaemia which can increase expression of PAI-1. Rabbits were randomly treated with intravenous 1-hr infusions of vehicle alone (control), insulin ( $37 \mu \mathrm{g} / \mathrm{kg}$ body weight), or proinsulin $(61 \mu \mathrm{g} / \mathrm{kg}$ body weight, equimolar to insulin) and maintained euglycaemic by glucose clamping. To maintain euglycaemia, blood glucose was monitored every $10 \mathrm{~min}$ and exogenous glucose $(20 \%)$ was infused at an adjusted rate through a separate venous catheter until the concentration of blood glucose was stable in the absence of continuing infusion (usually at about $3 \mathrm{~h}$ ). The concentration of insulin used $(1 \mathrm{U} / \mathrm{kg}$ body weight) was selected to yield concentrations in blood in the upper range of that seen in patients with Type II diabetes mellitus. The concentrations seen at $1 \mathrm{~h}$ (the time when the infusion of insulin, proinsulin, or vehicle was terminated) were $688 \pm$ $142 \mu \mathrm{U} / \mathrm{ml}$ for insulin and $44.2 \pm 2.8 \mathrm{nmol} / 1$ for proinsulin.

Activity of PAI-1 in plasma. Blood samples were acquired before infusions were initiated and $3 \mathrm{~h}$ later by which time increases in PAI-1 activity in blood had peaked. PAI-1 activity was assayed spectrophotometrically after incubation of samples with excess exogenous t-PA [6]. One arbitrary unit (AU) was defined as the amount of PAI- 1 activity that inhibited 1 IU of t-PA.

Quantification of PAI-1 mRNA in adipose tissue. Intra-abdominal adipose para-aortic tissue samples were acquired $3 \mathrm{~h}$ after the onset of infusions. RNA was extracted. Concentrations of PAI-1 mRNA and of GAPDH mRNA were quantified as described previously [6, 9].

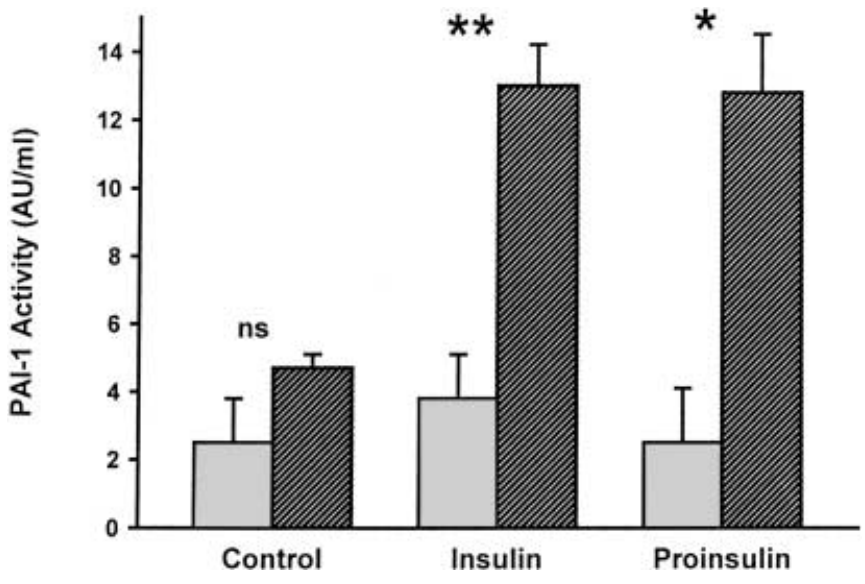

Fig 1. PAI-1 activity in blood from rabbits given infusions of insulin, proinsulin, or vehicle alone (control) over $1 \mathrm{~h}(0-1 \mathrm{~h})$. PAI-1 activity was assayed in samples obtained before initiation of infusions $(\square, 0 \mathrm{~h})$ and $(\mathbb{1}, 3 \mathrm{~h})$ later. Values are means \pm SEM in samples from four rabbits in each of the three groups with each value an average from duplicate measurements. $N S$, not significant. ${ }^{*} p=0.020,{ }^{*} p=0.004$

Statistical analysis. Results are means \pm SEM. The significance of differences between group means was assessed by ANOVA and two-tailed Student's t test for paired or unpaired observations as appropriate. Statistical significance was defined as a $p$ value of less than 0.05 .

\section{Results}

PAI-1 activity in blood. Activity of PAI-1 in blood before (at $0 \mathrm{~h}$ ) and $3 \mathrm{~h}$ after initiation of infusions are shown (Fig. 1). In control animals plasma PAI-1 activity did not change. By contrast, infusion of insulin increased PAI-1 activity 3.4-fold $(p=0.004)$. Infusions of proinsulin increased it 5.1-fold $(p=0.020)$. PAI-1 activity in blood after infusions of both insulin and proinsulin were significantly higher than those in control animals at comparable intervals after the onset of infusions (control compared with insulin, $p=0.003$; control compared with proinsulin, $p=0.009$; insulin compared with proinsulin, $p=\mathrm{NS}$ ).

Expression of PAI-1 in adipose tissue. Rabbits express only one PAI-1 mRNA species $(3.2 \mathrm{~kb})$ in contrast to humans in which two forms are typical [5]. Three hours after the onset of infusion, animals given insulin had a 2.5-fold higher expression of PAI-1 in visceral adipose tissue, and those given proinsulin had a 5.3fold higher expression of PAI-1 in intra-abdominal adipose tissue compared with values in control animals. All values were normalized for expression of GAP$\mathrm{DH}, \mathrm{mRNA}$. Thus, comparisons of results under the conditions studied were significant with the following $p$ values: control compared with insulin, $p=0.031$; control compared with proinsulin, $p=0.006$; and insulin compared with proinsulin, $p=0.049$ (Fig. 2). 

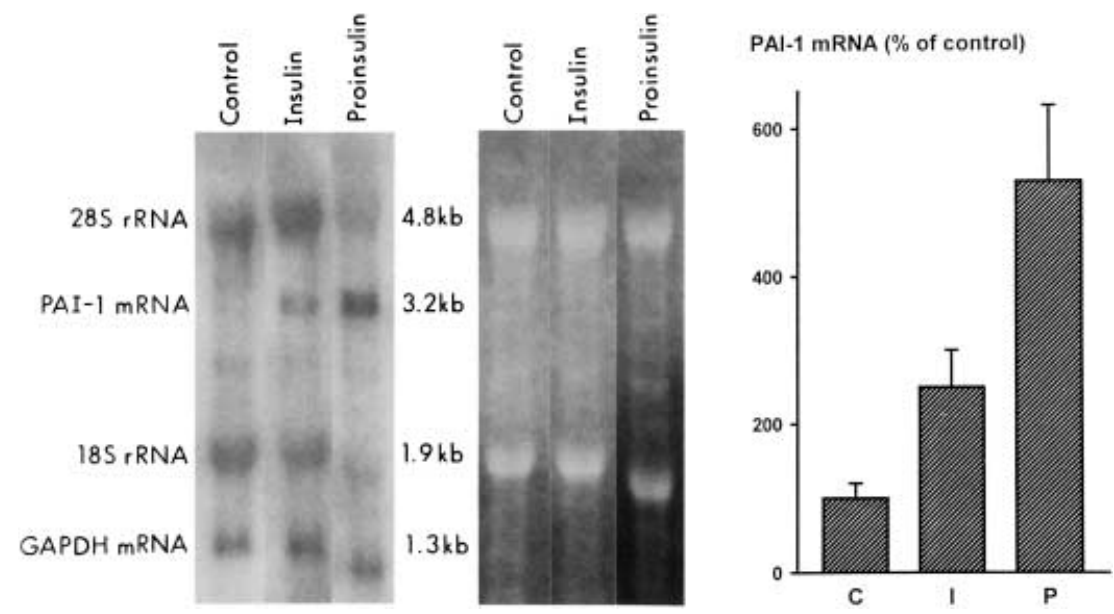

Fig. 2. PAI-1 mRNA in intra-abdominal adipose tissue from rabbits given infusions of insulin, proinsulin, or vehicle alone as a control over $1 \mathrm{~h}(0-1 \mathrm{~h})$. Tissues were harvested $3 \mathrm{~h}$ after initiation of infusions. Left: a representative autoradiogram showing PAI-1 mRNA and GAPDH mRNA used for normalization PAI-1 mRNA values for loading conditions. Centre: $28 \mathrm{~S}$ rRNA and $18 \mathrm{~S}$ rRNA in ethidium bromide-stained membranes assessed to verify equal loading and transfer of RNA to membranes. Right: PAI-1 mRNA results. Values are means \pm SEM of results of duplicate measurements from four rabbits in each of the three groups

\section{Discussion}

We found that the insulin precursor, proinsulin, increases expression of PAI-1 in intra-abdominal adipose tissue under euglycaemic conditions in vivo as does insulin itself. These results are consistent with previous results obtained with murine preadipocytes differentiated to adipocytes in vitro. Such cells exhibited increased expression of PAI-1 protein in the presence of insulin and TNF- $\alpha$, each alone and together synergistically [2]. Induction of PAI-1 protein as well as augmentation of PAI-1 mRNA by insulin have been observed in human adipose tissue explants and in differentiated adipocytes from murine $3 \mathrm{~T} 3$ cells [3]. However, PAI-1 expression did not increase in human adipocytes and cultured human stroma cells isolated with collagen in response to insulin. Thus, interactions between diverse cell types within adipose tissue could influence induction of PAI-1 expression by insulin and proinsulin. The specific cellular or subcellular locus of increased PAI-1 expression which we observed within the adipose explants is yet to be found.

Increased expression of PAI-1 induced by proinsulin in intra-abdominal adipose tissue in vivo has not been observed. However, others have shown that intraperitoneal injection of insulin in lean mice induces a several-fold increase in PAI-1 expression in epididymidal fat tissue [10]. The animals studied were not maintained under euglycaemic conditions. Thus, physiologic stress and increased glucocorticoid re- lease secondary to hypoglycaemia could have contributed to the increased PAI-1 expression observed [3]. Furthermore, although epididymidal fat cells resemble intra-abdominal adipocytes morphologically, they could differ functionally. Accordingly, we sought to determine whether intra-abdominal adipose tissue PAI-1 expression increased in vivo in response to insulin, proinsulin, to neither, or both.

Normal rabbits were selected for this purpose because of well established parallels between the regulation of endogenous fibrinolysis in rabbits and in humans $[5,6]$. We elected to use normal, in contrast to experimental, animal preparations manifesting features of Type II diabetes, to determine potential associations between induced hyper(pro)insulinaemia and increased expression of PAI-1 in visceral adipose tissue independent of other factors such as hyperglycaemia, dyslipidaemia, or insulin resistance prevalent in Type II diabetes which might influence PAI-1 expression alone or in combination with the infused agents. Obese animals were selected for the same reasons. In addition, in lean animals sufficient amounts of intra-abdominal adipose tissue would be difficult to acquire.

Blood concentrations of PAI-1 are influenced by expression of PAI-1 in adipose tissue, predominantly in intra-abdominal fat. In obese human subjects, weight loss induced surgically or with dietary regimens reduces blood concentrations of PAI-1 [11-14]. The change is closely related to changes in the mass of intra-abdominal fat. In fact, it reflects such changes more closely than it parallels changes in concentrations of metabolites such as triglycerides in blood [15]. Moreover, increased expression of PAI-1 in intra-abdominal as opposed to subcutaneous fat seems to be a determinant of changes in blood concentrations of PAI-1 in humans [16-18]. In concert, available data indicate that abdominal adipose tissue in addition to liver and endothelium is a major contributor to PAI-1 activity in blood.

In human subjects with hyperinsulinaemic states more than $50 \%$ of immunoreactive, insulin-like mol- 
ecules in circulating blood comprise precursors of insulin such as proinsulin. In contrast, under physiological conditions they account for only 10 to $20 \%$ of insulin-like molecules [4]. Although the interaction of proinsulin compared with insulin with the insulin receptor is modest $(1 \%)$, proinsulin is cleared more slowly from the circulation than is insulin, thereby intensifying and prolonging pathophysiological consequences of hyperproinsulinemia [19]. Our results show that proinsulin is at least as effective on a molar basis as insulin in inducing PAI-1 expression in intraabdominal adipose tissue and increasing PAI-1 activity in blood.

In conclusion, proinsulin as well as insulin in vivo under euglycaemic conditions induce expression of PAI-1 in intra-abdominal adipose tissue and increase PAI-1 activity in blood under euglycaemic conditions. Accordingly, attenuation of impaired fibrinolytic system capacity and its potentially adverse effects in accelerating atherosclerosis could result from normalization of concentrations of proinsulin and insulin in plasma, reduction of intra-abdominal fat mass, or both.

Acknowledgements. This study was supported in part by NIH grant HL-17646 and the Deutsche Forschungsgemeinschaft grant NO-214/1-1. The authors thank Lilly Research Laboratory, Eli Lilly Co., for human proinsulin; and L. Dales for secretarial support.

\section{References}

1. Juhan-Vague I, Alessi MC (1999) Regulation of fibrinolysis in the development of atherothrombosis: role of adipose tissue. Thromb Haemost 82: 832-836

2. Sakamoto T, Woodcock-Mitchell J, Marutsuka K, Mitchell JJ, Sobel BE, Fujii S (1999) TNF- $\alpha$ and insulin, alone and synergistically, induce plasminogen activator inhibitor-1 expression in adipocytes. Am J Physiol 276: C1391-C1397

3. Morange PE, Aubert J, Peiretti F et al. (1999) Glucocorticoids and insulin promote plasminogen activator inhibitor 1 production by human adipose tissue. Diabetes 48: 890-895

4. Nordt, TK, Schneider DJ, Sobel BE (1994) Augmentation of the synthesis of plasminogen activator inhibitor type-1 (PAI-1) by precursors of insulin: A potential risk factor for vascular disease. Circulation 89: 321-330

5. Fujii S, Sobel BE (1990) Induction of plasminogen activator inhibitor by products released from platelets. Circulation 82: 1485-1493
6. Nordt TK, Sawa H, Fujii S, Sobel BE (1995) Induction of plasminogen activator inhibitor type-1 (PAI-1) by proinsulin and insulin in vivo. Circulation 91: 764-770

7. Schatz H, Ammermann S, Laube H, Federlin K (1988) Bioactivity and pharmacokinetics of human proinsulin in comparison to human insulin after intravenous and subcutaneous injection. Horm Metab Res 20: 445-449

8. Alessi MC, Peiretti F, Morange P, Henry M, Nalbone G, Juhan-Vague I (1997) Production of plasminogen activator inhibitor 1 by human adipose tissue. Possible link between visceral fat accumulation and vascular disease. Diabetes 46: 860-867

9. Nordt TK, Kornas K, Peter K et al. (1997) Attenuation by gemfibrozil of expression of plasminogen activator inhibitor type- 1 induced by insulin and its precursors. Circulation 95: 677-683

10. Samad F, Loskutoff DJ (1996) Tissue distribution and regulation of plasminogen activator inhibitor-1 in obese mice. Mol Med 2: 568-582

11. Loskutoff DJ, Samad F (1998) The adipocyte and hemostatic balance in obesity. Studies of PAI-1. Arterioscler Thromb Vasc Biol 18: 1-6

12. Juhan-Vague I, Alessi MC (1997) PAI-1, obesity, insulin resistance and risk of cardiovascular events. Thromb Haemost 78: 656-660

13. Calles-Escandon J, Ballor D, Harvey-Berino J, Ades PA, Tracy RP, Sobel BE (1996) Amelioration of the inhibition of fibrinolysis in elderly obese subjects by moderate energy intake restriction. Am J Clin Nutr 64: 7-11

14. Kockx M, Leenen R, Seidell J, Princen HMG, Kooistra T (1999) Relationship between visceral fat and PAI-1 in overweight men and women before and after weight loss. Thromb Haemost 82: 1490-1496

15. Mavri A, Stegnar M, Krebs M, Sentocnik JT, Geiger M, Binder BR (1999) Impact of adipose tissue on plasma plasminogen activator inhibitor-1 in dieting obese women. Arterioscler Thromb Vasc Biol 19: 1582-1587

16. Shimomura I, Funahashi T, Takahashi M et al. (1996) Enhanced expression of PAI-1 in visceral fat: possible contributor to vascular disease in obesity. Nat Med 7: 800-803

17. Morange PE, Alessi MC, Verdier M, Casanova D, Magalon G, Juhan-Vague I (1999) PAI-1 produced ex vivo by human adipose tissue is relevant to PAI-1 blood level. Arterioscler Thromb Vasc Biol 19: 1361-1365

18. Yudkin JS, Coppack SW, Blumer K, Rawesh A, MohamedAli V (1999) Lack of evidence for secretion of plasminogen activator inhibitor-1 by human subcutaneous adipose tissue in vivo. Thromb Res 96: 1-9

19. Galloway JA, Hooper SA, Spradlin CT et al. (1992) Biosynthetic human proinsulin: review of chemistry, in vitro and in vivo receptor binding, animal and human pharmacology studies, and clinical trial experience. Diabetes Care 15: 666-692 